\title{
Cloth destruction and haemolysis with totally cloth-covered Starr-Edwards prostheses
}

\author{
M. SCHOT TENFELD, J . D. WISHEART, J . K. R OSS, \\ J.C.R. LINCOLN, and D. N. ROSS ${ }^{1}$
}

National Heart Hospital, London

\begin{abstract}
Four cases are described in which totally cloth-covered Starr-Edwards valves (model 2300) had to be removed. All were causing significant haemolysis, two in the absence of a peripheral leak. The principal operative finding was destruction of the Dacron covering the struts. Following replacement of these prostheses there was complete resolution of signs and symptoms. The possible causes of haemolysis and consequences of cloth destruction are discussed.
\end{abstract}

Thromboembolism is a major complication of the use of artificial cardiac valve prostheses and results in a significant annual morbidity and mortality (Duvoisin, Brandenburg, and McGoon, 1967; Rees, Miscall, Holswade, Castaneda, and Lillehei, 1970; Bloodwell, Okies, Hallman, and Cooley, 1969). The totally cloth-covered StarrEdwards prosthesis was introduced so that the valve might be totally incorporated and endothelialized and thereby rendered non-thrombogenic (Herr, Starr, Pierie, Wood, and Bigelow, 1968 ; Hodam, Starr, Raible, and Griswold, 1970). It has been shown that this process does occur (Braunwald and Morrow, 1968; Hodam, Starr, Herr, and Pierie, 1969 ; Braunwald and Bonchek, 1967), and that the incidence of late thromboembolism after surgery is reduced (Hodam et al., 1970). Some centres have therefore withdrawn anticoagulants after six months (Braunwald and Morrow, 1968; Reis, Glancy, O'Brien, Epstein, and Morrow, 1970). However, the incidence of early thromboembolism occurring before encapsulation has been achieved is not reduced (Hodam et al., 1970 ; Craige, Hutchin, and Sutton, 1970).

Other characteristics of this design have become apparent. The effective orifice area is considerably reduced compared to earlier non-cloth-covered models, and subsequent tissue ingrowth further reduces the diameter of the primary orifice (Reis et al., 1970 ; Kloster, Herr, Starr, and Griswold, 1969). Haemolysis in the absence of any peripheral regurgitation around the sewing ring has been reported (Hodam et al., 1970). Failure of incor-

1 Address for reprints: D. N. Ross, F.R.C.S., National Heart Hospital, Westmoreland Street, London, W.1. poration and endothelialization of the struts has been described (Reis et al., 1970). Reis and his colleagues (1970) also drew attention to the problem of cloth destruction and exposure of the metal cage.

We wish to report four cases in which totally cloth-covered Starr-Edwards valves were removed from the aortic position. Disruption of the cloth covering the struts and haemolysis were the principal findings.

\section{CASE REPORTS}

CASE 1 (15426) A 62-year-old man required resuture of a totally cloth-covered Starr-Edwards valve (size 9A, model 2300) five months after its insertion on account of peripheral detachment which resulted in aortic regurgitation due to the paravalvar leak. Seven months later he presented again with jaundice, haemolytic anaemia, and chest pain on exertion. A basal systolic thrill was palpable and the arterial pulse was slow rising and of diminished volume. Clinically, the valve appeared to be competent. The haemoglobin was $7.5 \mathrm{~g}$, the reticulocyte count was $21 \%$, the bilirubin was $1.2 \mathrm{mg} \%$, the serum lactic dehydrogenase was greater than 2,000 units, and the serum iron was $45 \mu \mathrm{g}$ per $100 \mathrm{ml}$.

Electrocardiography demonstrated sinus rhythm, a $P-R$ interval of 0.12 second, left axis deviation, QRS duration of 0.06 second, partial left bundle-branch block, left ventricular hypertrophy and strain indicated by $T$-wave inversion in leads V4 to V6 and S-T depression in V6. Serial chest radiographs indicated progressive cardiac enlargement after the re-suturing was performed. Cardiac catheterization failed to reveal any abnormality other than a left ventricular 


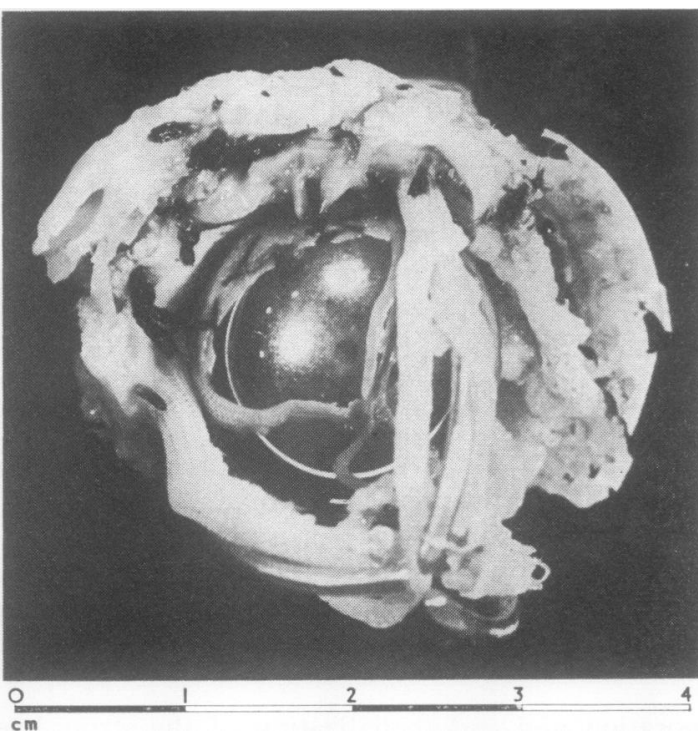

FIG. 1. Appaarance of Starr-Edwards valve after removal. Manipulation caused slight additional damage.

end-diastolic pressure of $15 \mathrm{mmHg}$. Aortography showed grade $1 / 4$ aortic regurgitation.

A third operation was performed at the National Heart Hospital one year after insertion of the prosthesis. Exposure of this valve showed the metal of two of the struts to be completely bare (Fig. 1). The Dacron lay free within the cage, except for its attachment to the base and apex of the struts. Dacron covered the outer aspect of the third strut but was destroyed on the inner surface. The prosthesis was excised and replaced with a fascia lata valve mounted on a $22 \mathrm{~mm}$ Ionescu frame (Ionescu and Ross, 1969 ; Ionescu, Ross, Deac, Grimshaw, Taylor, Whitaker, and Wooler, 1970). The postoperative course was uneventful and the valve remained competent. The patient is free of symptoms at present.

CASE 2 (16363) A 30-year-old woman presented 10 months after insertion of a totally cloth-covered StarrEdwards valve (size 9A, model 2300) in the aortic position at another hospital. She complained of chest pain and shortness of breath. There was a precordial thrill and a grade 5/6 systolic murmur. No diastolic murmur was audible. There was haemolytic anaemia; the haemoglobin was $4.4 \mathrm{~g}$, the reticulocyte count had risen to $21 \%$, the bilirubin was $1.3 \mathrm{mg} \%$, serum haptoglobin was $4 \mathrm{mg} \%$, and plasma haemoglobin was $33 \mathrm{mg} \%$.

The electrocardiographic findings were: sinus rhythm, P-R interval $0 \cdot 18$ second, normal electrical axis, QRS duration $0 \cdot 10$ second, partial left bundlebranch block, left ventricular hypertrophy, T-wave inversion and $S-T$ segment depression in V3 to V6.
At cardiac catheterization the systolic gradient across the aortic valve was $40 \mathrm{mmHg}$, and the meanc left atrial pressure was $20 \mathrm{mmHg}$ with an ' $a$ ' wave $\frac{\bar{\sigma}}{\bar{c}}$ of $30 \mathrm{mmHg}$.

Sixteen months after the first replacement a second $\stackrel{\mathbb{Q}}{\varrho}$ operation was performed at the National Hearto Hospital. It was found that while the struts were not $\rightarrow$ enveloped, the sewing ring was well incorporated so. that the primary orifice was narrowed by tissue in- $\vec{\overrightarrow{ }}$ growth. In addition, the mitral valve was found to be stenotic, showing typical rheumatic changes, and $\overrightarrow{\vec{x}}$ there was also subaortic muscular stenosis.

The Starr-Edwards aortic valve was excised and replaced with a fascia lata valve mounted on a $20 \mathrm{~mm}$ iv Ionescu frame and a subvalvular myotomy was carried $\vec{G}$ out. As open commissurotomy of the mitral valve 6

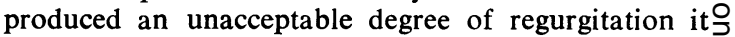
also was replaced with a $24 \mathrm{~mm}$ frame-mounted fascia lata valve. Her postoperative course was uneventful and both valves remain competent. There has been no recurrence of symptoms or haemolysis.

CASE 3 (17749) A 56-year-old man with a rheumatic history presented with haemolysis and retrosternal. pain radiating to the left arm. Seven months earlier an aortic valve replacement with a totally clothcovered Starr-Edwards prosthesis (size $11 \mathrm{~A}$, model $\bar{\partial}$ 2300) had been performed at another hospital. Four months after that operation there had been a febrile $\mathbb{\perp}$ illness during which Staphylococcus aureus was isolated from blood cultures. Subsequently, an early흠 diastolic murmur of aortic incompetence became 3 audible. During an acute haemolytic episode the haemoglobin fell to $4 \cdot 1 \mathrm{~g}$, the reticulocyte count rose? to $42 \%$, the serum bilirubin was $2.3 \mathrm{mg} \%$, serum haptoglobin was $16 \mathrm{mg} \%$, the plasma haemoglobin $\overline{0}$ was $70 \mathrm{mg} \%$, serum lactic dehydrogenase was greater than 2,000 units, and Schumm's test for methaemo- $\frac{x}{\sigma}$ globinaemia was positive. Haemosiderin was present 3 in the urine.

On admission to the National Heart Hospital the clinical findings were unchanged. Electrocardiography revealed sinus rhythm, a P-R interval of $0 \cdot 16$ second,, left axis deviation, severe left ventricular hypertrophy, and T-wave inversion in leads V5 and V6. Fluoro-O scopy showed unrestricted ball travel, and on aorto- $N$ graphy there was mild grade $2 / 4$ aortic incompetence. Coronary arteriography was normal.

Eleven months after the original valve replacement a second operation was performed at the National $\sigma$ Heart Hospital. Pressure measurements at operation indicated that there was a gradient of $35 \mathrm{mmHg}$ across $\stackrel{0}{\subseteq}$ the prosethesis with a left ventricular end-diastolic $\mathbb{D}$ pressure of $15 \mathrm{mmHg}$. Following aortotomy, the pre- ${ }^{+}$ sence of intimal thickening on the aortic wall related to the cage was noted. Only the sewing ring was incorporated, and the covering on the struts was worn, $\stackrel{\mathbb{Q}}{\triangle}$ exposing the metal on the inner aspect of the cage. There was a peripheral leak in the region of the right $\frac{}{\sigma}$ and non-coronary sinuses, and after excision of the valve a small excavated area was identified and pre- $\varnothing$ 
sumed to be the site of the postoperative infection. The valve was replaced with a fascia lata valve mounted on a $22 \mathrm{~mm}$ Ionescu frame, and the aortotomy was closed. The valve proved to be competent and the patient had an uneventful postoperative course.

CASE 4 (1738) A 44-year-o:d man presented with angina and haemolysis three months after insertion of a totally cloth-covered Starr-Edwards valve (size 10A, model 2300) at another hospital. A coarse basal systolic thrill was palpable. The haemoglobin was $7 \cdot 2$ g. with a reticulocyte count of $10 \%$. The bilirubin was $2.5 \mathrm{mg} \%$, the serum lactic dehydrogenase was greater than 2,000 units, Schumm's test for methaemoglobinaemia was positive, and the serum iron was $109 \mu \mathrm{g} \%$. Haemolysis increased with exercise.

The electrocardiogram showed sinus rhythm, a P-R interval of 0.12 second, normal electrical axis, QRS duration of 0.04 second with partial right bundlebranch block, left ventricular hypertrophy, and T-wave inversion in leads V4 to V6. Aortography showed restricted ball travel but there was no regurgitation.

Eight months after the valve replacement a second procedure was carried out at the National Heart Hospital. Under normothermic cardiopulmonary bypass it was noted that the sinus ridges restricted excursion of the ball by impinging on the cage. The sewing ring was well incorporated but the Dacron

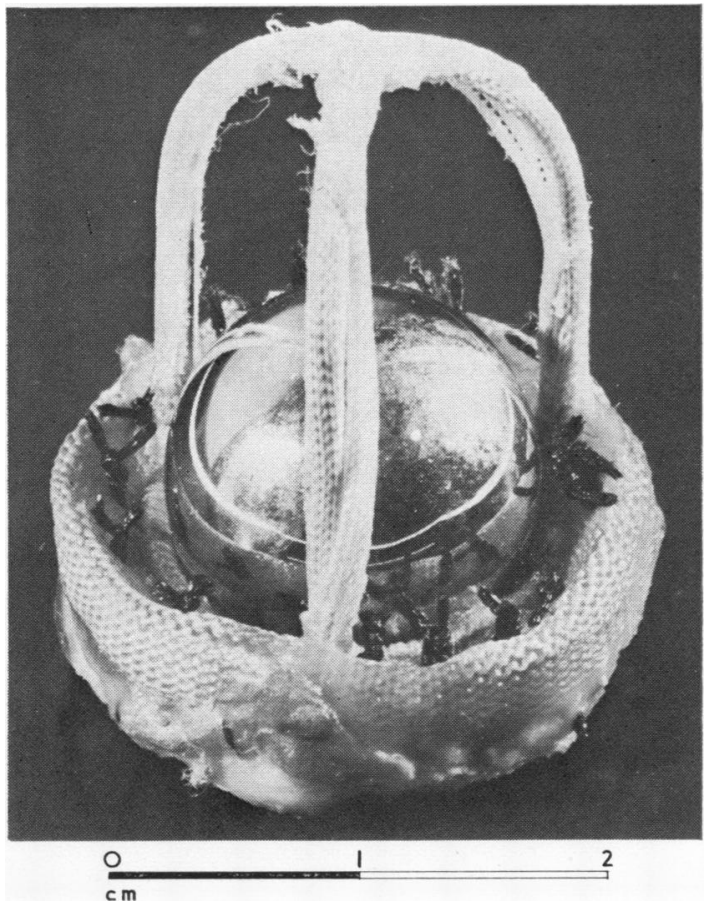

FIG. 2. Note the damaged Dacron and the exposed metal on the inner aspect of all three struts. was worn on the inner aspect of the struts, permitting the metal ball to strike the bare metal of the cage (Fig. 2). There was no associated peripheral leak. Staph. aureus was cultured from the prosthesis. The valve was replaced with a fascia lata valve mounted on a $22 \mathrm{~mm}$ Ionescu frame. This valve was competent and the patient's postoperative course was uneventful.

\section{DISCUSSION}

Although valve replacement is performed on a routine basis at many centres, the surgeon continues to be confronted by a variety of prosthetic and biological materials for this purpose. The number of models described and the continuing flow of modifications indicate that the ideal substitute has not yet been developed, and therefore the relative advantages of biological and artificial valves require continual re-assessment.

Each of the four patients discussed had received a totally cloth-covered Starr-Edwards prosthesis, model 2300 (Table I). Three patients required removal of the prosthesis within one year, and the

T A B L E

SUMMARY OF CLINICAL FINDINGS

\begin{tabular}{|c|c|c|c|c|c|c|c|}
\hline \multirow{3}{*}{ Case } & \multirow{3}{*}{$\begin{array}{c}\text { Pros- } \\
\text { thesis } \\
\text { Model } \\
\text { Size }\end{array}$} & \multirow{3}{*}{$\begin{array}{c}\text { Time } \\
\text { in } \\
\text { Situ } \\
\text { (months) }\end{array}$} & \multirow{2}{*}{\multicolumn{2}{|c|}{$\begin{array}{c}\text { Tissue } \\
\text { Incorporation }\end{array}$}} & \multirow{3}{*}{$\begin{array}{l}\text { Cloth } \\
\text { Destruc- } \\
\text { tion } \\
\text { Metal } \\
\text { Exposed }\end{array}$} & \multicolumn{2}{|c|}{ Haemolysis } \\
\hline & & & & & & & \\
\hline & & & $\begin{array}{c}\text { Sewing } \\
\text { Ring }\end{array}$ & Strut & & Present & $\begin{array}{l}\text { pheral } \\
\text { Leak }\end{array}$ \\
\hline 1 & 2300 & 12 & + & - & + & + & + \\
\hline 2 & $\begin{array}{c}9 . \\
2300 \\
9 A\end{array}$ & 16 & + & - & - & + & - \\
\hline 3 & 2300 & 11 & + & - & + & + & + \\
\hline 4 & $\begin{array}{l}2300 \\
10 A\end{array}$ & 8 & + & - & + & + & - \\
\hline
\end{tabular}

fourth at 16 months. The striking feature was cloth destruction and exposure of strut metal in three cases, and in one patient the Dacron had been dislodged from two of the three struts. None of the struts was covered by tissue. All patients complained of angina and presented with significant haemolysis, and in two this occurred in the absence of a peripheral leak around the sewing ring. There were obstructive features in three of the four valves; in one, there was tissue ingrowth narrowing the primary orifice, in another there was a measured gradient of $35 \mathrm{mmHg}$, and in the third, ball travel was restricted by the sinus ridges of the aorta.

The immediate cause of cloth destruction is the poppet striking the inner aspect of the cage. However, such destruction has not occurred in the majority of cases. In the patients reported here there is an association between the disintegra- 
tion of Dacron and failure of tissue encapsulation. These two findings may be causally related in one or both of two ways: (a) non-incorporation may be more likely to lead to disintegration, and (b) excessively worn Dacron may prevent incorporation.

The consequences of cloth destruction are potentially serious. First, Dacron emboli are almost inevitable in view of the condition of the cloth. Tefion embolus attributed to such fragmentation has recently been described by Niles (1970). Secondly, if the cloth becomes free of the strut, as we have described, its presence within the cage may lead to increased turbulence and restricted ball travel. Thirdly, the valve remains potentially thrombogenic when there is exposed strut metal following cloth destruction.

Haemolysis, present in all four cases, occurred in two of the patients despite the absence of a peripheral leak. It is generally considered that haemolysis must be associated with regurgitation around the sewing ring, although findings similar to ours have recently been reported (Hodam et al., 1970 ; Spencer, Reed, Clauss, Tice, and Reppert, 1970). The relative importance of damaged foreign material, exposed metal, turbulence, and reduced effective orifice area as possible causes of haemolysis remains to be elucidated.

\section{REFERENCES}

Bloodwell, R. D., Okies, J. E., Hallman, G. L., and Cooley, D. A. (1969). Aortic valve replacement: long-term results. J. thorac. cardiovasc. Surg., 58, 457.

Braunwald, N. S., and Bonchek, L. I. (1967). Prevention of thrombus formation on rigid prosthetic heart valves by the ingrowth of autogenous tissue. J. thorac. cardiovasc. Surg., 54, 630.
- and Morrow, A. G. (1968). Tissue ingrowth and the rigid heart valve. J. thorac. cardiovasc. Surg., 56, 307.

Craige, E., Hutchin, P., and Sutton, R. (1970). Impaired function of cloth-covered Starr-Edwards mitral valve $\overline{\bar{\rho}}$ prosthesis. Detection by phonocardiography. Circula- $\overparen{\mathbb{D}}$ tion, 41, 141.

Duvoisin, G. E., Brandenburg, R. O., and McGoon, D. C. ֶ (1967). Factors affecting thromboembolism associated $\overrightarrow{0}$ with prosthetic heart valves. Circulation, 35, Suppl. 1, p. 70.

Herr, R. H., Starr, A., Pierie, W. R., Wood, J. A., and $\vec{\omega}$ Bigelow, J. C. (1968). Aortic valve replacement: a review of six years' experience with the ball-valve $\vec{x}$ prosthesis. Ann. thorac. Surg., 6, 199.

Hodam, R., Starr, A., Herr, R., and Pierie, W. R. (1969). Early clinical experience with cloth-covered valvular prostheses. Ann. Surg., 170, 471.

Raible, D., and Griswold, H. (1970). Totally cloth-covered prostheses: a review of two years' clinical experience. Circulation, 41, Suppl. 2, p. 33.

Ionescu, M. I., and Ross, D. N. (1969). Heart-valve replace-ment with autologous fascia lata. Lancet, 2, 335. —— Deac, R., Grimshaw, V. A., Taylor, S. H., Whitaker, W., and Wooler, G. H. (1970). Autologous $\overrightarrow{0}$ fascia lata for heart-valve replacement. Thorax, 25, 46.

Kloster, F. E., Herr, R. H., Starr, A., and Griswold, H. E. (1969). Hemodynamic evaluation of a cloth-covered Starr-Edwards valve prosthesis. Circulation, 39, Suppl. 1, p. 119.

Niles, N. R. (1970). Teflon embolism from Starr-Edwards valves. J. thorac. cardiovasc. Surg., 59, 794.

Rees, J. R., Miscall, B. G., Holswade, G. R., Castaneda, A., and Lillehei, C. W. (1970). Late results of valve replace- $\overrightarrow{\vec{B}}$ ment. Surgery, 67, 141.

Reis, R. L., Glancy, D. L., O'Brien, K., Epstein, S. E., and Morrow, A. G. (1970). Clinical and hemodynamic assessment of fabric-covered Starr-Edwards prosthetic valves. J. thorac. cardiovasc. Surg., 59, 84.

Spencer, F. C., Reed, G. E., Clauss, R. H., Tice, D. A., and Reppert, E. H. (1970). Cloth-covered aortic and mitral $\stackrel{\sim}{\times}$ valve prostheses. Experiences with 113 patients. J. thorac. cardiovasc. Surg., 59, 92. 